\title{
Innovative teaching methods in dental education
}

\author{
(1) Supriya Bhat, (1) Ananya Madiyal, (1) Gogineni Subhas Babu
}

Nitte (Deemed to be University), AB Shetty Memorial Institute of Dental Sciences (ABSMIDS), Department of Oral Medicine and Radiology, Mangalore, India

Date submitted:

30.05.2020

Date accepted:

13.07.2020

Online publication date:

15.03.2021

\section{Corresponding Author:}

Ananya Madiyal MDS, Nitte (Deemed to be University), AB Shetty Memorial Institute of Dental Sciences (ABSMIDS), Department of Oral Medicine and Radiology, Mangalore, India

ananyamadiyal@gmail.com

ORCID:

orcid.org/0000-0002-0907-3244

Keywords: Education, teaching, learning, lecture, students

\begin{abstract}
Health professionals have often acknowledged that their profession does not prepare them for teaching. Hence the teaching style has been predominantly the traditional lecture based system. In this review, we get a gist of the innovative teaching methods, which have gained acceptance in the recent years, and how the implementation of these has become crucial for effective teaching learning process. Problem based learning, case based team based learning, microteaching and flipped classroom are some of the innovations discussed. The dental faculty also need to undergo a series of training to be well equipped with these methods, and also the institutes wanting to implement the above methods should have the infrastructure, so that the students are also well equipped and motivated to utilize the innovations which in turn will help them think and acquire knowledge in an effective, systematic manner.
\end{abstract}

\section{Introduction}

The faculty of dental education in India has been adapting newer and innovative methods in imparting lessons to the undergraduate students. Some of these methods have gained acceptance and are being utilized as a part of the curriculum. As a result of multitude of changes such as modifying social determinants of health, an exponential increase in technology, and a steep rise in health care, dental education also has a changed scenario (1). Dental education has developed from a self-learnt and self-proclaimed profession in the past to a one involving formal education and recognized competencies (2). Health professionals have acknowledged that their education does not equip them for teaching. However, due to an increasing expectation of the society from the health professionals, it necessitates them to be well versed in teaching techniques/ skills and be qualified adequately (3).

\section{Problem Based Learning}

In 1990, The Faculty of Odontology in Malma, Sweden was the first to introduce problem based learning (PBL) in the field of dental education (3). PBL has been described as a method where a problem aids as a catalyst for learning. In this approach, the students describe the problem and develop learning targets which are needed to promote their perception of the problem. The method involves miniature batches of students engaged together and in collaboration with facilitators in order to accomplish learning $(4,5)$.

A prime necessity for a PBL curriculum is that "the problem always comes first". This maybe conferred as one of the ground guidelines of the program and has a substantial significance on the format of the curriculum (4). Primarily, the syllabus is formulated based on problems rather than disciplines, with emphasis on combined learning, instead of segregation into basic and clinical sciences. In the next step, it is led by 
circumstances which makes learning simple, for instance smallgroup teaching, a student focused approach, effective study and self-reliant learning. Next, it is decided by outcomes, such as enhanced practical knowledge, skill advancement and impetus required for constant learning along with the development of self-appraisal techniques (6).

The advantages of $\mathrm{PBL}$, when compared to traditional methods, comprise of an enhanced assimilation of basic as well as clinical techniques, mainly refined communication, team work, independent learning, along with an enhanced inclination and satisfaction of participating together on a problem. In health education, instructors have an advantage when associating clinical cases with basic sciences, by equipping students to figure out clinical problems which depend on key fundamentals and prior knowledge. Moreover, the techniques acquired and accomplished in the course, teamwork, delegation along with the use of relevant literature are paramount when it comes to professional tasks following graduation (7).

The utilization of problems to impart the curriculum content via PBL pedagogy demands the organizing group of the curriculum to primarily identify the predetermined program outcomes and later develop an array of problems providing the content, which is required to accomplish the fixed objectives. With regard to this, the establishment as well as sequencing of problems is crucial to cater to a comprehensive set of learning outcomes along with a systematic advancement of the establishment of the competency. A PBL pedagogy constitutes of three important factors, which need to be incorporated to allow the promotion of an inquiry-driven learning zone. These constituents - the problems, the small group learning, and the student centered environment-should be present to achieve a fruitful conclusion (4).

PBL has been incorporated in dental institutes all over the world in the past decade. This is an emerging concept and its implementation has been increasing. Dental institutes, which are looking forward to this concept, should be aware of the modifications needed in the infrastructure, and the significance of faculty development, new curriculum materials and students admission procedure (4).

\section{Microteaching}

Microteaching is a mini teaching confrontation which is aimed to create recent techniques and improvise old ones (8). Allen(9) developed this concept in the 1960s at the Stanford Teacher Education Program. It is an approach for students who aspire to be teachers to improvise upon their techniques in an adjuvant peer learning set up. The pupils will observe that their associates experience similar struggles, weaknesses and strengths. New techniques will be recalled and learnt by watching their associates and consulting with their group leader (10).
Students improvise upon their descriptive skills by converting cumbersome chapters into learnable entities with the help of leading coordinators, associating the lecture utilizing topics spanning the psychomotor and cognitive learning realms by employing questioning and pauses. This method asks for a change in focus from, "What am I going to cover" to "What are my students going to learn?" (10).

Microteaching comprises of several stages such as briefing phase, preparation phase, teaching stage, an evaluation by the class and overseer followed by either preparing for the upcoming class or learning of the same technique (11). In the briefing phase, exercises are included to help the student face the camera and help them increase their confidence. The preparation stage requires the students to devise their own teaching layout, and the scenarios of which they would want to present in class with an established basic skill. The teaching phase will have the students to impart their lectures in a scaleddown session for a time frame between five and twenty-five minutes. Viewing along with evaluation commenced with selfappraisal on positive and negative points seen, improvements to be made and if the preparations were of a particular set standard $(10,12)$. The physical, psychological and emotional dimensions of the teaching process were analysed (12). The final process of Debriefing takes place after each student had accomplished a skill. This is usually held on the last day of the class, where a final acclamation was made of each student $(10,12)$.

\section{Case Based Team Based Learning}

In the recent years, case based - team based learning (TBL) models has been utilized in teaching strategies (13). According to studies, interactive teaching learning methods such as these can pass on sustainable knowledge along with a change in performance leading to immense satisfaction among students when compared to traditional lecture classes (14). Lecture classes are not considered as the optimal method for establishing in-depth and long lasting understanding of the subject matter learned by the students (13).

In the late 1970s, Larry Michaelson at Oklahoma University originally developed TBL. As the strength of his class grew from 40-120 students, it necessitated him to design a new pedagogic paradigm, which was learning in miniature groups (15). It is efficient in enabling students to help each other during smallgroup discussions in a larger class along with preparation prior to a class. All group activities within a larger class can be conducted by one teaching personnel. This is in contrary to $\mathrm{PBL}$, which has small-group activities and usually requires independent tutors for each group to monitor the progress (16). Compartmentalized space for group activities is not needed, as they continue in an open space allowing effective interaction among the groups (17). Literature states that TBL for dental education has been followed in Periodontics (18), Oral medicine (19), Oral Radiology 
(13), Removable (20) and Fixed Prosthodontics (17). All the above studies reported higher student satisfaction with better performance when compared to conventional lectures.

Case based learning (CBL) is an interactive, studentcentered, instructor-led learning approach, which was first begun in a Medical school in Newfoundland, Canada. This methodology encourages active learning by employing clinical case scenarios, which mirror real life experiences that students will encounter during the clinical stage of their medical education (21). Cases are generally presented as problems which equip the students with patient details such as case history and laboratory results. Active learning ensues when students have the opportunity to have more interaction with the case. This empowers them to generate knowledge rather than only receive, enhancing their skills for sharing with other pupils in a group (2224). Active learning is a student oriented process, which makes the learners to be liable for their learning in a self - directed, peer-assisted seeking of new information (25). Self-directed learning is one of the advantages of CBL. It also strengthens the logic, collaborative as well as communication skills in students (22-24).

\section{Flipped Classroom}

At its basic level, flipped classroom is a method of assigning learner's didactic material, conventionally covered in lectures, to be learnt prior class, along with utilizing classroom hour for interactive and active learning (26). This methodology was noticed when a YouTube video, "The Flipped Classroom" was posted by Sams and Bergmann (27) on 16 $6^{\text {th }}$ December 2010. This requires the facilitators to previously record the lectures and posting in an online portal for pupils to observe on their own, thus dedicating the class hours for learning activities. This also makes the students responsible enough to have a basic understanding of the topic, which makes them participate well in discussions and other exercises. The faculty organizes content, establishing interactive participation, which requires the pupils to understand along with providing expert insight and evaluation (28). Park and Howell (29), in 2015, described the model of a flipped classroom in a predoctoral dental program; second year Dental Anatomy for thirty-six pupils. There was reluctance from the faculty with regard to the implementation, especially when they were challenged with a heightened task in view of the duration and struggle required for interactive activities. Although faculty was hesitant, positive feedback was obtained after implementation. Students found this format as entertaining, interactive as well as collaborative in comparison to the conventional lecture format. Along with technological issues, they also felt that the group discussions, at times, were chaotic. Shapiro et al. (30) reported that interactive online modules were effective in imparting to the students, regarding identification as well as reporting of child abuse in pediatric dentistry. Though the module was effective, they would not opt for it as an alternative to the lecture based approach. It was also reported to be effective in educating students on periodontal diagnosis and treatment planning as per a study conducted by Lee and Kim (31). This approach involves a more advanced commitment by faculty as well as the pupils with technology. It creates a platform for involving faculty members of a department in the era of online teaching and learning in a relaxed and healthy environment (32).

Flipped classroom has been initiated at all educational levels from Kindergarten to University and have been implemented in a variety of ways. Generally, video lectures made by the instructor or third parties are utilized to convey the content, even if online collaborative discussions, digital research and text readings could be used. There has been a significant change in the quantity of online educational videos over the last 15 years. Podcasts, YouTube, the Khan Academy and such in order to make the introduction of a flipped classroom simpler and economical (33).

Some of the active learning techniques include problem solving cases, small group learning, mini case studies, videos, clinical recreations, role playing exercises, student presentations, test based learning, debates, lab work, peer-review etc (34).

Though this method has advantages, it has also faced several challenges. Some students may have limited access to videos. For the facilitator, preparing videos is often an arduous task. There will be students who still want the traditional lecture system. They should be motivated enough to watch the videos (34).

\section{Conclusion}

Teaching in all fields has progressed a lot from the conventional lecture based system. Though the conventional lecture based system continues to be the main method in many institutes, others have adopted innovative methods for the benefits of students as well as the teachers. Teaching in dental education has also seen a wide variety of changes. As dental education continues to embrace new methodologies, it is necessary to broaden research to analyze the impact on students as well as faculty. Prior to implementing a method, the institutions should see that they have sufficient infrastructure required for the particular method. This is very important for the implemented innovation to progress in a smooth manner. Appropriate training should be given to the faculty, as well as the students, prior to implementing a teaching method. Also, efforts should be taken to determine that the implemented innovative methods are being conducted effectively, and not just for the sake of implementation. Constant monitoring should be done if the students are effectively benefitted from these methods. Feedback should be collected from the students as well as the 
teachers. This is crucial in determining the effectiveness of the system, and also to address the challenges, if any.

\section{Ethics}

Peer-review: Externally peer-reviewed.

\section{Authorship Contributions}

Concept: S.B., A.M., G.S.B., Design: S.B., Literature Search: S.B., A.M., G.S.B., Writing: S.B., A.M.

Conflict of Interest: No conflict of interest was declared by the authors.

Financial Disclosure: The authors declared that this study received no financial support.

\section{References}

1. Nagda SJ. Changing trends in dental education - Paradigm Shift. J Dent Specialities. 2015;3:86-88.

2. Depaola DP. The evolution of dental education as a profession, 1936-2011, and the role of the journal of dental education. J Dent Educ. 2012;76:14-27.

3. Rohlin M, Petersson K, Svensater G. The Malmo model: a problem-based learning curriculum in undergraduate dental education. Eur J Dent Educ. 1998;2:103-114.

4. Fincham AG, Shuler CF. The changing face of dental education: the impact of PBL. J Dent Educ. 2001;65:406421.

5. International Dental Problem-Based Learning Network. Use of problem-based learning in Canadian and U.S. dental schools: results of a survey. J Can Dent Assoc. 2002;68:26.

6. Alrahlah A. How effective the problem-based learning (PBL) in dental education. A critical review. Saudi Dent J. 2016;28:155-161.

7. Onyon C. Problem-based learning: a review of the educational and psychological theory. Clin Teach. 2012;9:22-26.

8. Heyorth R. Microteaching: a bilingual approach. CUHK Educ J. 1981;9:45-56.

9. Allen DW. Micro-teaching: A New Framework for In-Service Education. High School Journal. 1966;49:355-362.

10. Kamboj M, Kamboj P, George J, Jha UK. Microteaching in Dental Education. J Dent Educ. 2010;74:1243-1244.

11. Brown G. Using microteaching to teach lecturers. London: Educational Media International; 1976.

12. Sana EA. Improving teaching through microteaching. Ann Acad Med Singap. 2007;36:452-453.

13. Kumar V, Gadbury Amyot CC. A case - based and teambased learning model in oral and maxillofacial radiology. J Dent Educ. 2012;76:330-337.

14. Smits PBA, Verbeek JHAM, de Buisonjé CD. Problem based learning in continuing medical education: A review of controlled evaluation studies. BMJ. 2002;324:153156.

15. Michaelsen LK, Knight BA, Fink LD. Team-based learning: a transformative use of small groups in college teaching. Sterling, VA: Stylus Publishing; 2004.

16. Matsuka $\mathrm{Y}$, Nakajima $\mathrm{R}$, Miki $\mathrm{H}$, et al. A problem- based learning tutorial for dental students regarding elderly residents in a nursing home in Japan. J Dent Educ. 2012;76:1580-1588.

17. Takeuchi H, Omoto K, Okura K, et al. Effects of team-based learning on fixed prosthodontic education in a Japanese School of Dentistry. J Dent Educ. 2015;79:417-423.

18. Pileggi R, O'Neill PN. Team-based learning using an audience response system: an innovative method of teaching diagnosis to undergraduate dental students. J Dent Educ. 2008;72:1182-1188.

19. Shetty SR, Babu GS, Castelino R, Hegde S, Rao PK, Kishor S. Case based Team Based Learning: A Novel Method for teaching Orofacial Syndromology to Dental Undergraduate Students. Educ Health (Abingdon). 2015;28:112-113.

20. Haj-Ali R, Al Quran F. Team-based learning in a preclinical removable denture prosthesis module in a United Arab Emirates dental school. J Dent Educ. 2013;77:351-357.

21. Thistlethwaite JE, Davies D, Ekeocha S, et al. The effectiveness of case-based learning in health professional education. A BEME systematic review: BEME Guide No. 23. Med Teach. 2012;34:421-444.

22. Tsou KI, Cho SL, Lin CS, et al. Short-term outcomes of a near-full PBL curriculum in a new Taiwan medical school. Kaohsiung J Med Sci. 2009;25:282-293.

23. Malher X, Bareille N, Noordhuizen JPTM, Seegers H. A case-based learning approach for teaching undergraduate veterinary students about dairy herd health consultancy issues. J Veterin Med Educ. 2009;36:22-29.

24. Engel FE, Hendricson WD. A case-based learning model in orthodontics. J Dental Educ. 1994;58:762-767.

25. Özbıçakçı Ş, Bilik Ö, İntepeler ŞS. Assessment of goals in problem-based learning. Nurse Educ Today. 2012;32:7982.

26. Hurtubise L, Hall E, Sheridan L, Han H. The flipped classroom in Medical education: engaging Students to Build competency. J Med Educ Curric Dev. 2015;2:35-43.

27. Sams A, Bergmann J. The flipped classroom. YouTube, 2010. At: youtube/2H4RkudFzlc

28. Bergmann J, Sams A. Flip your classroom: reach every student in every class every day. Washington, DC: International Society for Technology in Education; 2012.

29. Park SE, Howell TH. Implemention of a flipped classroom educational model in a predoctoral dental course. J Dent Educ. 2015;79:563-570. 
30. Shapiro MC, Anderson OR, Lal S. Assessment of a novel module for training dental students in child abuse recognition and reporting. J Dent Educ. 2014;78:11671175.

31. Lee C, Kim SW. Effectiveness of a Flipped Classroom in Learning Periodontal Diagnosis and Treatment Planning. J Dent Educ. 2018;82:614-620.

32. Bohaty BS, Redford GJ, Gadbury-Amyot CC. Flipping the Classroom: Assessment of Strategies to Promote Student-
Centered, Self-Directed Learning in a Dental School Course in Pediatric Dentistry. J Dent Educ. 2016;80:13191327.

33. Ghosh S. Combination of didactic lectures and caseoriented problem - solving tutorials toward better learning: perceptions of students from a conventional medical curriculum. Adv Physiol Educ. 2007;31:193-197.

34. Murphy PJ. Changing the landscape of learning in dentistry. J Dent Oral Biol. 2016;1:1-4. 